\title{
MUSKY TWEETS: INFORMATION TRANSFER IN THE AGE OF UNBRIDLED SOCIAL MEDIA
}

\author{
Xiaoman Duan \\ Sam Houston State University • Huntsville, Texas \\ Robert Stretcher \\ Sam Houston State University • Huntsville, Texas
}

\section{INTRODUCTION}

Announcements concerning public corporations have traditionally been carefully crafted statements in pre-announced venues where the opportunity for wide absorption of the information is quickly achieved. This is because problems can arise from spilling critical information in ways that favor few investors or send erroneous signals to those paying attention. In recent years, however, a greater number of social media posts have occurred from politicians, celebrities (either existing ones or those quickly created by viral postings) and even from top managers in corporations, with or without prior consultation with the company's directors. One of the most notorious posting CEOs, Elon Musk, has posted many eccentric statements about his own views and statements of seeming authority about the company he still runs as CEO (no longer Chairman of the Board after some lawsuits), Tesla Corporation. In some cases, the information relayed in his "tweets" has been provocative and surprising to financial market participants. In one case, a tweet implied that the firm would be taken private, and that funding for the action had been secured. This created a tremendous reaction in the firm's stock price, both positive after the tweet and negative after the validity of Musk's statement was challenged. Whether it was meant to be manipulative or was just an inadvisable public rant on Twitter, the posts attracted the attention of the Securities Exchange Commission and other regulatory agencies, and placed Musk under legal and regulatory scrutiny.

This case provides a brief history of Elon Musk's recent (as of November 2018) publicly acclaimed behavior as a basis for classroom discussion. It is appropriate for use in finance, economics, and even business communication courses. We anticipate that a 30-45 minute discussion is in order after a preparatory reading of the case. It is easily supplemented with additional materials either provided by the instructor or gathered by students. 


\section{THE AGE OF SHARING ON A WHIM}

In the decade from 2009 until the present, social media has grown in scale and public reach. With that growth, the brashness and audacity, even vulgarity of the comments and reactions to those comments seem to escalate. Often, posts or reactions to posts on social media take the other extreme, overly-sensitive rants equally radical in their wording. Perhaps it shouldn't be so surprising that individuals of prominent stature such as leaders of countries or Chief Executive Officers of large corporations would take to social media and post extreme statements, or that others, as self-appointed "fact checkers" or "righteous social conscience," would rebut those statements. In fact, Twitter strategies have even been suggested for executives wishing to use the platform to bring about predictable public response that is likely to positively affect a corporate objective (Malhotra and Malhotra 2016).

A fine line is crossed, however, when readers of a tweet from a company's executive officer interpret a statement meant to be informal and humorous as a valid signal concerning the policies or decisions actually made at the company. If this is the case, then regulators have shown that they consider the communication to be exposed to the same scrutiny as official and perhaps carefully crafted statements made by the firm's management via traditional communication channels.

\section{ELON MUSK TWEETS}

A series of tweets from Elon Musk underscore the importance of this realtime communication medium. It was obvious early in Musk's tweeting career that the financial markets carefully observed his tweets, trying to glean information that could positively affect positions in Tesla stock, or derivatives based on Tesla stock. Many of his tweets are written with ambiguity, and have numerous variations in interpretation, as evidenced by the flurry of retweets and responses that surface after Musk's initial tweets.

\section{TIMELINE OF ELON MUSK'S TWITTER ACTIVITIES}

In this section, we document the major twitter events created by Elon Musk in a chronological order. When introducing each event, we incorporate detailed background to provide more depth into the events, and we also discuss the financial market implications on his twitter posts. 


\section{June 4, 2010}

Musk posted his first tweet and since then, he has composed more than 7100 tweets over the 9-years interval, making him one of the most active Chief Executive Officers (CEOs) on social media from a major US public companies. He has also built a huge fan base of 25.5 million twitter followers. ${ }^{1}$ His direct, unpredictable and often quite frank communication style via social media often surprises investors, shakes the market and attracted controversy to himself and his companies. More often than not, we observe that his tweets have the ability to move the financial market.

\section{March 30, 2015}

On March 30, 2015, Musk made a surprising announcement on twitter that a "new and major product line" that is "not a car" will be released by Tesla in a month. Although he did not reveal any product details, the stock market reacted strongly to his announcement. Tesla's stock price jumped more than 3 percent in 10 minutes following his twitter post, adding $\$ 900$ million to Tesla's market value. ${ }^{2}$ Largely consistent with the market speculations, it turned out Tesla was unveiling a home battery and a utility scale battery. ${ }^{3}$

\section{Elon Musk}

@elonmusk

Major new Tesla product line -- not a car -- will be unveiled at our Hawthorne Design Studio on Thurs 8pm, April 30

O5.6k $Q 1.1 \mathrm{k}$ people are talking about this 9:35 AM - Mar 30, 2015

\footnotetext{
${ }^{1}$ The statistics are gathered from Elon Musk's twitter site at: https://twitter.com/elonmusk

${ }^{2}$ News and data source is from Forbes and Pando: https://www.forbes.com/sites/briansolomon/2015/03/30/elon-musk-bootstesla-stock-with-major-new-product-tweet-tease/\#304b0d293f9a; https://pando.com/2015/03/30/elon-musk-created-nearly1b-in-value-today-with-a-single-tweet/

${ }^{3}$ Here is one example on the market speculations: https://www.businessinsider.com/this-is-going-to-be-teslas-new-productline-2015-3; The product information can be found here: https://www.wsj.com/articles/tesla-to-announce-grid-scalebattery-pack-home-battery-april-30-1429659606
} 


\section{April 1, 2018}

April 1 is a traditional day for pranks and Musk seemed to be in a good mood to participate in such activities. Musk posted on twitter a series of April fool's day jokes centered on the electric car maker's bankruptcy. In his first twitter post, Musk made a statement that Tesla had gone "completely and totally bankrupt." He followed up with additional posting, including him passed out drunk against a side of a model 3 car and held a cardboard sign that reads "Bankwupt!" In theory, a joke cannot carry any real material information on the company and therefore should not affect Tesla's stock price. However, it turned out to be an inopportune time for Musk to publicly post jokes about his company's demise. There were already quite a few tensions in the market in regard to Tesla's performance around the time, and investors did not handle his jokes lightly. We discuss the series of negative events that the company went through in the preceding month in the following paragraphs.

To start, the company was stranded in a "production hell" of its first massmarketed car, the Model 3. Not enough cars were being produced on time to meet the demand from consumers. ${ }^{4}$ There were also growing concerns that the company was running out of cash.

A week before his twitter posts, Moody's Investor Service, one of the big three credit rating agencies in the U.S., cut Tesla's corporate debt rating from B3 to B2. The purpose of the credit ratings is to provide assessment of a company's ability to repay their debt. A downgrade is bad news because it broadcasts to the market the credit rating agency's belief that the company has a higher risk of defaulting on its debt. According to Moody's, the downgrade reflected a "significant short fall" in the production of the company's model 3 electric car, and a tight liquidity position in which the company would have to raise a large amount of capital to meet its liquidity needs and pay off its maturing debts. ${ }^{5}$

In addition, on March 29th, Tesla issued a recall of 123,000 model S electric cars around the world because of the defect with the power steering component. The recall was the largest recall ever for Tesla, and the massive number of recalled car represented almost half of all the cars that the company had built as of that date. ${ }^{6}$

To add to the company's problems, the U.S. National Transportation Safety Board (NTSB) was conducting an investigation into a fatal Tesla Model X accident

\footnotetext{
${ }^{4}$ The news is from the following source: https://money.cnn.com/2018/03/28/news/companies/tesla-model-3-cash-crunch/ index.html

${ }^{5}$ https://www.moodys.com/research/Moodys-downgrades-Teslas-corporate-family-rating-to-B3-senior-notes--PR_381481

${ }^{6}$ https://www.nbcnews.com/business/autos/tesla-recalls-almost-half-cars-it-ever-built-shares-tank-n861421
} 
in Mountain View, California in March. Tesla admitted that Autopilot driving system was involved in the fatal crash.

Against this backdrop, Tesla was already having the worst monthly performance in years and Musk's April fool's day joke sent Tesla shares plunging further. On the day Musk posted his bankruptcy joke, Tesla's stock price was down over 7 percent, indicating investors' high level of anxiety about the company's prospects. $^{7}$

\section{Elon Musk}

@elonmusk

Tesla Goes Bankrupt

Palo Alto, California, April 1, 2018 -- Despite

intense efforts to raise money, including a lastditch mass sale of Easter Eggs, we are sad to report that Tesla has gone completely and totally bankrupt. So bankrupt, you can't believe it.

O131k 28.6k people are talking about this

4:02 PM - Apr 1, 2018

\section{Aug 7, 2018}

Musk dropped a bombshell into the internet community and to the financial markets when he announced his intention to take Tesla private on twitter. His first tweet at 10:48 am (PST) states that he is "considering taking Tesla private at $\$ 420$ " per share price. He further states that the funding needed for this massive buyout is "secured", although he did not provide further information on the source of the funding.

Amid some questions from Tesla's investors, Musk added another tweet at 11:00 am (PST) saying that he "hopes all the current investors remain with Tesla" even after the company transformed to a private company.

In a follow-up tweet at 11:13 am (PST), he lays out two options for the existing shareholders: "either to sell at $\$ 420$ or stay with the company and go private." At 12:36 pm (PST), he further states that the deal has confirmed "investors' support"

\footnotetext{
${ }^{7}$ https://www.wsj.com/articles/tesla-shares-sink-as-musk-jokes-about-bankruptcy-1522682691

${ }^{8}$ The statistics is from Wall Street Journal article: https://www.wsj.com/articles/elon-musks-twitter-account-am-consideringtaking-tesla-private-at-420-1533661152
} 
and the only reason that the deal is not finalized is that it is still "contingent to a shareholder's vote."

Why did his tweets on taking the company private draw lots of attention from the public? If the deal went through, the company would be valued at above $\$ 70$ billion, making it the largest take-private transaction in the history of the mankind. ${ }^{8}$ Tesla's stock price was closed at a price of $\$ 343.84$ on the previous trading day and according to Musk, the existing shareholders can sell their shares at $\$ 420$. This indicates that the electric car company is willing to offer a deal premium of $22 \%$ above its current stock price in order to attract the existing shareholders to sell their stakes.

Later the same day, Musk explained more on his rationale for taking Tesla private on the official corporate blog. He argued that taking Tesla private is for "creating the environment for Tesla to operate best." 9 Giving up the public status of the company means that Tesla can be less distracted to the wild swings in its stock market performance, and it allows the company to pursue long-term goals instead of immediate profits. A privately held Tesla also does not need to file quarterly earnings reports and there will be no more short sellers, which distort the company from its most efficient and long-term mission driving operations. Musk held roughly $20 \%$ of the company and this would largely remain the same after the company became private.

Although he did not disclose his funding sources at the time he tweeted his intention for Tesla to go private, one of the market speculations was that the oilrich Saudi Arabia could be the major fund provider. One the same day, the market learned that not long ago the Public Investment Fund of Saudi Arabia (PIF), one of the world's largest sovereign wealth funds, had acquired close to $5 \%$ stake in Tesla. ${ }^{10}$

On Aug 13, Musk provided an update on the whole go-private event on the official corporate blog and answered some important questions including why he made the announcement publicly and the source of the funding. He confirmed that he had been in talks with the Saudi sovereign wealth fund several times over the past two years. During their most recent meeting on July 31st, the official from Saudi side had "strongly expressed his support for funding a going private transaction for Tesla at this time." Therefore, when Musk walked out of the meeting, he had strong belief that the deal could be reached at his proposed $\$ 420$ if they end up pursuing the going-private path.

According to Musk, the reason that he made this important piece of information public through his twitter account social media is to ensure fairness in information

\footnotetext{
${ }^{9}$ The full statement can be found at: https://www.tesla.com/en_GB/blog/taking-tesla-private?redirect=no

${ }^{10}$ The information is obtained from the following news source: https://www.reuters.com/article/us-tesla-musk-saudi/saudisovereign-fund-pif-has-bought-a-below-5-percent-stake-in-tesla-source-idUSKBN1KS1YT
} 
release to all Tesla's investors: Tesla's retail investors and big investors can obtain this important news at the same time. He thought it was the right thing to do.

Elon Musk

@elonmusk

Am considering taking Tesla private at $\$ 420$. Funding secured.

○8.7k $Q 22.7 \mathrm{k}$ people are talking about this

10:48 AM - Aug 7, 2018

\section{Elon Musk $\bullet$}

@elonmusk

My hope is *all current investors remain with Tesla even if we're private. Would create special purpose fund enabling anyone to stay with Tesla. Already do this with Fidelity's SpaceX investment.

O 8.5k $\$ 518$ people are talking about this

11:00 AM - Aug 7, 2018

\section{Elon Musk $\$$}

@elonmusk

Shareholders could either to sell at 420 or hold shares \& go private

O19k $Q 1.3 \mathrm{k}$ people are talking about this $\quad$ 11:13 AM - Aug 7, 2018

Elon Musk

@elonmusk

Investor support is confirmed. Only reason why this is not certain is that it's contingent on a shareholder vote.

O19k 8.7k people are talking about this 
On Aug 24, Musk posted a statement on his corporate blog: "I believe the better path is for Tesla to remain public." He quoted the reasons for reaching this decision: the existing shareholders prefer to keep Tesla public, and going private could present more challenges than he initially anticipated.

\section{Stock Price Reaction}

Musk's tweets on taking Tesla private were followed by dramatic upward movement in Tesla's stock price on the same day. By the time Nasdaq halted the trading of Tesla's shares, Tesla's shares were already up by more than 7 percent. The reason for Nasdaq to halt the trading in less than two hours from his first tweet was to wait for more information and further clarification to come. During the halting period, Musk continued his tweets and Tesla also posted a letter Musk wrote to its employee on his corporate blog. After slightly more than an hour and a half after halting, Tesla trading was resumed and Tesla's stock price continued to rise and was closed at $\$ 379.57$, gaining about 11 percent in value. ${ }^{11}$ The trading volume had also exhibited more than three times its norm, from an average daily volume of 8.7 million shares to 29.8 million shares. $^{12}$

\section{SEC Prosecution}

The day after Musk posted his taking-private tweets, the Wall Street Journal reported that the officials at the Securities Exchange Commission were making inquiries on his statements to check if the disclosed information was supported by facts. At that time, it was not clear whether the SEC had opened a formal enforcement investigation. ${ }^{13}$ In summary, the potential troubles that he was facing were on three fronts: stock market manipulation, releasing untrue or incomplete material information, and not following the right procedure to release the information.

On September 27th, the SEC filed a formal complaint against Elon Musk and Tesla. According to the complaint, Musk made a series of "materially false and misleading" statements using his personal twitter account on August 7. Those statements had led to "significant confusion and disruption in the market" (SEC, 2018). For example, he claimed that he was considering taking Tesla for private at

\footnotetext{
${ }^{11}$ The above price information is from the following news source: https://www.nytimes.com/2018/08/07/business/teslastock-elon-musk-private.html; https://seekingalpha.com/news/3379457-tesla-trading-live-updates

${ }^{12}$ The above information on trading volume is from the following news source: https://seekingalpha.com/news/3379457tesla-trading-live-updates

${ }^{13} \mathrm{https} / /$ www.wsj.com/articles/sec-has-made-inquiries-to-tesla-over-elon-musks-taking-private-tweet1533757570 ?mod=hp_lead_pos2
} 
$\$ 420$ per share and the funding for this massive transaction had been secured. The SEC argues that in reality, he had never confirmed, nor seriously discussed the deal with the $\$ 420$ price offer with the Saudi SWF or with any potential funding source.

Musk also claimed that the going-private deal had won investors' confirmed support and the only reason the deal was not certain at this point is that it was subject to a shareholder vote. According to the SEC, Musk had never obtained the confirmed support from Tesla's investors and there were other contingencies that he had not taken into serious consideration. Therefore, it was misleading to claim the deal had a good likelihood of occurring.

One of the penalties sought by the SEC was to ban Elon Musk from serving as an officer or director of a public company. In other words, he could be forced to step down from his CEO role or the chairman of the board role of Tesla.

\section{TWEETS SUMMARY}

Twitter is a casual platform for making brief statements (given its word limit) compared to Tesla's official communication outlets or other media outlets. It allowed Musk to engage in impulsive and direct conversations with his followers, including Tesla's investors. It is natural for a twitter user to spend less time to contemplate short posts, or instantly reply to other users, even when a post deserves more scrutiny before publication.

An important lesson, however, needs to be learned. As the chairman and CEO of a public company, an icon on corporate innovation, a celebrity with great publicity, and a prolific user of twitter with 25 million followers, Musk has the duty to convey accurate (and avoid misleading) material information to the public. This message is echoed by SEC as one of its officer states that: "An officer's celebrity status or reputation as a technological innovator does not give license to take those responsibilities lightly." 14

\section{SEC SETTLEMENT}

On September 29, the news came out that Musk had reached a settlement with the SEC. On October 4, Musk posted a tweet to ridicule the SEC, that the acronym SEC stands for "Shortseller Enrichment Commission.” Tesla's stock price

\footnotetext{
14 The above statement is from Steven Peikin and the statement can be found at the SEC news release: https:/www.sec.gov/ news/press-release/2018-219

15 The price information can be found here: https:/www.cnbc.com/2018/10/05/tesla-shares-drop-nearly-5percent-after-muskmocks-sec-on-twitter.html
} 
went down by $7 \%$, indicating investors were anxious on the increased uncertainty of the settlement caused by his oral attack on SEC. ${ }^{15}$

On October 16, a federal judge approved the settlement. Among the agreed terms, Musk and Tesla would evenly split a total of $\$ 40$ million in fines, which the SEC sought to return to "harmed investors." Besides financial penalties, Musk was to step down from his chairman role before the November 13 deadline, and he wouldn't be eligible to be chairman again for a period of three years. In addition, Tesla would appoint two independent directors to the board and set up a system to oversee its CEO’s public communications

\section{Elon Musk $\bullet$}

@elonmusk

Just want to that the Shortseller Enrichment Commission is doing incredible work. And the name change is so on point!

O36.6k 8 8.9k people are talking about this

2:16PM - Oct 4, 2018

When being asked by a twitter follower how he feels about his tweets that ended up costing him \$20 million, Musk replied with two words: "Worth it."16

On November 8, Tesla announced that Robyn Denholm would replace Elon Musk as the new chairman, serving as the head of Tesla's board of directors. Robyn Denholm had been a board member of Tesla since 2004 and she was considered to have fewer business and personal ties with Musk. ${ }^{17}$

On Oct 29, Musk issued another surprise to the market when he tweeted that he had removed his Tesla titles and he would now be referred to as the "Nothing of Tesla." In his follow-up tweet, he decided to keep his CEO role as he discovered that a company needs to have a president, along with treasurer and secretary, to fulfill legal requirements.

\footnotetext{
${ }^{16}$ See the twitter post available at: https://twitter.com/elonmusk/status/1056012218897059841?lang=en

${ }^{17}$ This statement is from Wall Street Journal: https://www.wsj.com/articles/tesla-names-robyn-denholm-as-chairman-toreplace-elon-musk-1541659771
} 


\section{Elon Musk}

@elonmusk

Deleted my Tesla titles last week to see what would happen. I'm now the Nothing of Tesla. Seems fine so far.

\section{$\overline{\text { A TEACHING STRATEGY }}$}

This case provides background on Elon Musk's publicly acclaimed behavior as a basis for classroom discussion. We suggest that it be assigned as preparation for subsequent classroom discussion. The materials may easily be supplemented with other items at the discretion of the professor, which could either be assigned to students for collection, or provided by the professor.

The case is appropriate for use in finance, economics, and even business communication courses. It often produces a lively discussion among students, and is usually good for a 30-45 minute discussion. In more advanced courses, the case could simply be assigned to students as preparation for class discussion. In less advanced courses, and at the professor's option, guidance questions could be assigned such as:

1. What are the company's major businesses? Who is the CEO and board of directors? What are the CEO's responsibilities?

2. What are public companies? What are private companies? What are the differences?

3. Which stock exchange does Tesla list its shares on?

4. When did Tesla first become a public company? What is this process called?

5. What are the drawbacks of being a public company that made Musk want to go private?

6. Why was Tesla stock being shorted? Why did Musk hate the stock being shorted?

7. What was Musk's rationale for taking Tesla Private?

8. Why did Musk choose to make the announcement public via twitter? Was his intention dishonorable? 
9. What lessons could Musk learn from the events? Do you think he learned the right lessons?

10. Is verbal desire sufficient for making a claim that funding is secured? Why does SEC say it is misleading to investors? Why is securing that funding so important? Why does it even matter to the investors?

11. What happened to Tesla's stock price when his statements came out? Can you explain why the stock price is affected?

\section{REFERENCES}

https://twitter.com/elonmusk

https://www.forbes.com/sites/briansolomon/2015/03/30/elon-musk-boots-teslastock-with-major-new-product-tweet-tease/\#304b0d293f9a

https://pando.com/2015/03/30/elon-musk-created-nearly-1b-in-value-today-with-asingle-tweet/

https://www.businessinsider.com/this-is-going-to-be-teslas-new-productline-2015-3

https://www.wsj.com/articles/tesla-to-announce-grid-scale-battery-pack-homebattery-april-30-1429659606

https://money.cnn.com/2018/03/28/news/companies/tesla-model-3-cash-crunch/ index.html

https://www.moodys.com/research/Moodys-downgrades-Teslas-corporate-familyrating-to-B3-senior-notes--PR_381481

https:/www.nbcnews.com/business/autos/tesla-recalls-almost-half-cars-it-everbuilt-shares-tank-n861421

https://www.wsj.com/articles/tesla-shares-sink-as-musk-jokes-aboutbankruptcy-1522682691

https://www.wsj.com/articles/elon-musks-twitter-account-am-considering-takingtesla-private-at-420-1533661152

https://www.tesla.com/en_GB/blog/taking-tesla-private?redirect=no https://www.reuters.com/article/us-tesla-musk-saudi/saudi-sovereign-fund-pif-hasbought-a-below-5-percent-stake-in-tesla-source-idUSKBN1KS1YT https://www.nytimes.com/2018/08/07/business/tesla-stock-elon-musk-private.html; https://seekingalpha.com/news/3379457-tesla-trading-live-updates https://seekingalpha.com/news/3379457-tesla-trading-live-updates https://www.wsj.com/articles/sec-has-made-inquiries-to-tesla-over-elon-muskstaking-private-tweet-1533757570?mod=hp_lead_pos2 
https://www.sec.gov/news/press-release/2018-219

https://www.cnbc.com/2018/10/05/tesla-shares-drop-nearly-5percent-after-muskmocks-sec-on-twitter.html

https://twitter.com/elonmusk/status/1056012218897059841?lang=en

https://www.wsj.com/articles/tesla-names-robyn-denholm-as-chairman-to-replaceelon-musk-1541659771

Malhotra, Claudia K., and Arvind Malhotra (2016). How CEOs can leverage Twitter. MITSloan Management Review 57(2), Winter, 73-79.

SEC Complaint—Elon Musk: https://www.sec.gov/litigation/complaints/2018/ comp-pr2018-219.pdf

\section{SHORT BIOGRAPHICAL SKETCH OF AUTHORS}

Dr. Robert Stretcher is a Professor of Finance at Sam Houston State University. He earned his $\mathrm{PhD}$ in Finance and Monetary Economics from the University of Tennessee in 1995. His research focuses on empirical market studies, applied finance and finance education. Dr. Stretcher has held prominent positions in the Academy of Economics and Finance, Financial Education Association, and Institute of Finance Case Research, and has served as Editor and on editorial boards of various finance journals.

Dr. Xiaoman Duan is an Assistant Professor of Finance at Sam Houston State University. She earned her $\mathrm{PhD}$ in Finance from the University of Oklahoma in 2017. Her research interests include corporate finance and international finance. 